\title{
Literatura trágica y filosofía del espíritu*
}

\author{
Tragic literature and the philosophy of mind
}

\author{
Gonzalo Portales \\ Universidad Austral de Chile, Instituto de Filosofía y Estudios Educacionales, \\ Apartado postal 567, Valdivia, Chile, \\ e-mail: gportale@uach.cl
}

A Jorge Eduardo Rivera, en el octogésimo aniversario de su nacimiento

Literatura trágica y filosofía del espíritu se refiere no sólo al modo como la Estética de Hegel incorpora este género literario de la Antigüedad en el canon de las expresiones artísticas, sino que desarrolla además el significado que el arte trágico obtiene al interior del sistema, especialmente en la parte que constituye la filosofía del espíritu, como ejemplaridad de la acción fundada en el ethos y que Hegel nombra con el vocablo alemán Sittlichkeit.

Palabras clave: literatura, filosofía.

Tragic literature and the philosophy of the soul refer not only to the way Hegel's Estética incorporates this ancient literary genre into the canon of artistic expressions. These concepts also develop the meaning that tragic art obtains inside the system. The part that constitutes the philosophy of the mind is an example of the action founded in the ethos that Hegel names with the German word sittlichkeit.

Key words: literature, philosophy.

En la actualidad, cuando oímos o leemos -en un contexto no coloquial- la palabra griega tragedia $\left(\tau \rho \alpha \gamma \omega \delta \delta^{\prime} \alpha\right)$, pensamos directamente en un género literario de la antigüedad clásica vinculado a las artes representativas o al inicio del teatro ( $\theta \dot{\varepsilon} \alpha \tau \rho o v)$, sin que ello nos evoque, en la mayoría de los casos, de manera directa la figura de ó $\tau \rho \alpha ́ \gamma o \zeta$, es decir, del arcaico macho cabrío destinatario de la oda puesta en escena. Lo que paulatinamente hemos ido dejando de lado es el antecedente de fiesta dionisíaca y, por lo tanto, de celebración orgiástica al servicio de ritos beneficiosos para la fertilidad, que se encuentra al origen de esa conmovedora ceremonia fálica que ha borrado las huellas de su procedencia. Algunos ejemplos de la lírica arcaica nos permiten aún

\footnotetext{
* Este trabajo es producto del proyecto Fondecyt $\mathrm{N}^{\mathrm{o}} 1060104$.
} 
conjeturar parcialmente las formas de los cantos a Dioniso, como por ejemplo en la así llamada Plegaria de Anacreonte, quien en busca de correspondencia amorosa por parte de Cleóbulo no vacila en invocar los "juegos" en los que la divinidad se rodea de Eros, Ninfas y la diosa Afrodita. O los restos fragmentarios denominados ó $\rho \alpha ́ \mu \alpha \tau \alpha$ $\tau \rho \alpha \gamma \iota \kappa \alpha ́$ atribuidos a Píndaro, de los que se ha conservado el ditirambo a Cerbero, en el que el coro lírico describe un "éxtasis salvaje que en la fiesta de Dioniso se apodera de los mismos dioses" (Lesky 1989, 224-225). ${ }^{1}$ La enciclopedia Pauly, por su parte, cree poder probar que el más antiguo de los testimonios correspondería al siguiente fragmento de Arquíloco: "Sé cantar el ditirambo, hermosa canción de Dioniso, cuando

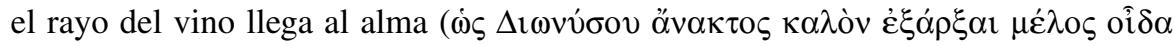

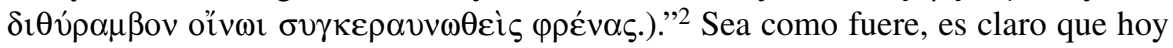
-mediatizados por la exigencia monolátrica y por la desacralización de la sexualidad, propias de la tradición judeocristiana- experimentamos cierta incomprensión y extrañeza con respecto a esta festividad de la religiosidad arcaica.

Nuestra presente distancia sin embargo, a pesar de encontrarse mediatizada por esta enorme alteración religioso-cultural, no es, en muchos aspectos, significativamente mayor que aquella que ya alejaba al griego clásico del sentido primario de la festividad arcaica, pues cuando se instaura la competencia trágica, acontecimiento de política cultural del cual proceden todas las tragedias conocidas, la oda al macho cabrío ya había dejado de ser una ceremonia puramente religiosa y había obtenido el status propio de la obra de arte. Si atendemos al testimonio de Diógenes Laertius en

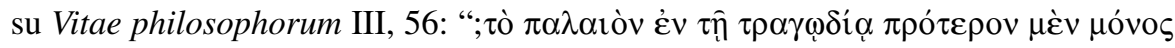

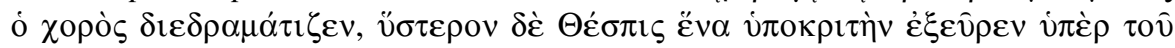

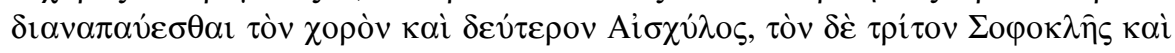

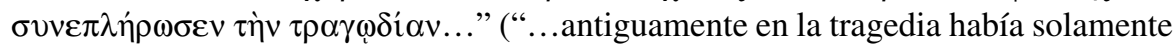
el coro, después Tespis introdujo un actor, a fin de que el coro descansase; luego Esquilo le dio dos actores, Sófocles tres, y de esta forma se fue perfeccionando la tragedia...") $)^{3}$, constatamos que es muy poco lo que en la misma Antigüedad se sabía con respecto a la evolución de la tragedia en la época anterior a los concursos atenienses, dirigidos por Tespis, bajo la tiranía pisístrata. Estudios etnológicos han intentado demostrar que la tradición ditirámbica y el culto mismo a la divinidad dionisíaca tendrían su origen en un componente sincrético de la época arcaica -tal vez habría que decir con más precisión, de la época de la formación-, y que por lo mismo no

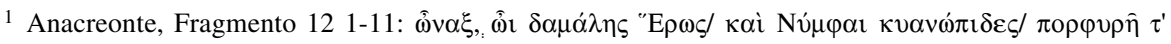

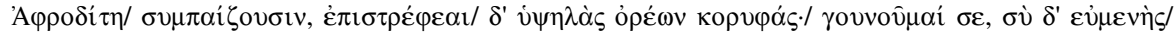

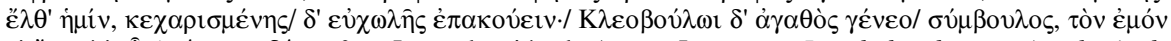

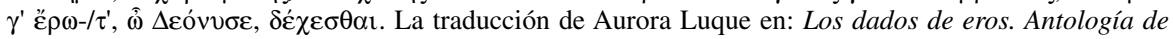
poesía erótica griega (Madrid 2000, p. 101): "Señor al que acompañan en su juegos/ Eros el dominante, las Ninfas de azulada/ pupila y Afrodita rosada como púrpura/ y que vas recorriendo/ las elevadas cimas de los montes,/ tus rodillas abrazo: ven benévolo a mí,/atiende el ruego y quede satisfecho,/ hazte buen consejero de Cleóbulo/ y que al menos mi amor, oh Dioniso, acepte". Cf. tambien Lírica griega arcaica, Madrid 2001, p. 318. En el caso de Píndaro, la mera expresión $\delta i \theta v ́ \rho \alpha \mu \beta o \varsigma$ designa ya el carácter dionisíaco del canto poético aludido, cf. el fragmento 70b en: Píndaro: Odas y fragmentos, Madrid 1984, p. 339.

2 Cf. Pauly, t. II., p. 106.

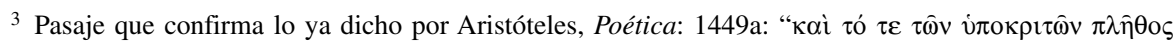

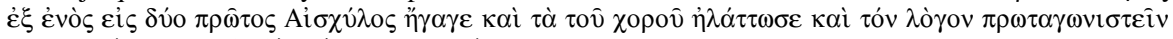

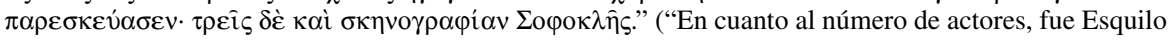
el primero que lo elevó de uno a dos, disminuyó la intervención del coro y dio el primer puesto al diálogo. Sófocles introdujo tres y la escenografía").
} 
responderían a una raíz puramente griega. ${ }^{4}$ Aun cuando no disponemos de ninguna obra de Tespis, la documentación recogida por la bibliografía especializada (cf. Pauly V., p. 755) subraya el hecho de que este primer poeta trágico -triunfador de las fiestas dionisíacas en 535 y 533 a. C.- proviniese de la isla de Icaria frente a la costa jónica ${ }^{5}$, pues se ha podido determinar que allí se practicaba un culto dionisíaco y se poseía un teatro ya a comienzos del siglo VI a.C. La misma fuente señala que este autor habría introducido la máscara ( $\pi \rho o ́ \sigma \omega \pi \mathrm{ov})$ en la representación teatral, continuando así una tradición proveniente del primitivo culto sacerdotal en el que el portador de la misma se transformaba en el ente representado, haya sido éste una divinidad, un demonio o un animal (cf. Pauly III., p. 1063).

Tal vez se deba, precisamente, a este origen algo misterioso y vinculado a ceremonias orgiásticas, que la tragedia, ya entendida técnicamente como obra de arte, haya encontrado, sin embargo, resistencia, tanto de parte de la clase política ateniense como así también de algunos de sus más connotados filósofos clásicos. Si otorgamos credibilidad a la no siempre confiable Vitae philosophorum (I, 59-60), nos enteramos de que Solón habría prohibido a Tespis "la representación y enseñanzas de tragedias",

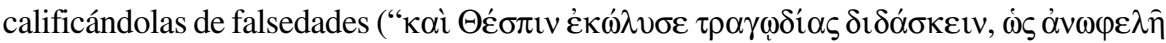

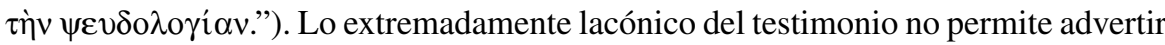
con claridad las posibles causas de tal censura, pero lo más probable es que no se haya tratado, en este caso, ni de una diferencia filosófico-moral ni tampoco de una controversia estética, sino que su argumento correspondería, más bien, a la manifiesta resistencia política de Solón frente a la tiranía ateniense. La misma fuente (Vitae philosophorum I, 66-67) reproduce una supuesta carta de Solón a Pisístrato en la que si bien lo llama

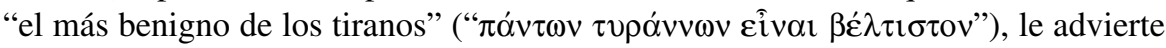
que él, al igual que la mayoría de los atenienses, aborrecce la tiranía (monarquía) y que considera mejor ser gobernado por muchos ( $\delta \eta \mu$ кр $\alpha \tau \varepsilon i \sigma \theta \alpha \imath)$ que por uno solo. Podría pensarse, acorde a esta información, que el sabio legislador presiente en el inicio de la dramaturgia pública de la tragedia una elemental distracción popular al servicio de la ilegítima autocracia ( $\tau$ $\rho \alpha v v i ́ \alpha$ )

Radicalmente inverso es el modo, a mi juicio, y opuestos también los motivos, por los que Platón se enfrenta con tanta severidad a los efectos políticos de la poesía trágica. Casi al final de su controvertida República (603 a-c), previene sobre el ca-

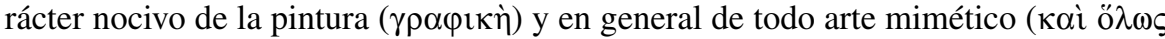

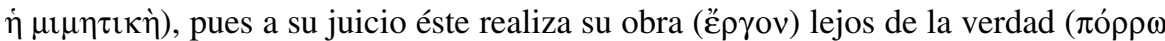
$\mu \grave{\varepsilon} v \tau \hat{\eta} \varsigma \dot{\alpha} \lambda \eta \theta \varepsilon \dot{i} \alpha \varsigma$ ) y se dirige a lo que en nosotros se encuentra a su vez lejos de la sabiduría ( $\pi$ ó $\left.\rho \omega \delta^{\prime} \alpha \hat{v} \varphi \rho o v \eta ́ \sigma \varepsilon \omega \varsigma\right)$. Unas líneas más adelante, se insiste en el hecho de que lo que se acaba de concluir no sólo posee validez para lo que concierne a la vista, es decir, para la pintura, sino también para el arte imitativo que se dirige al

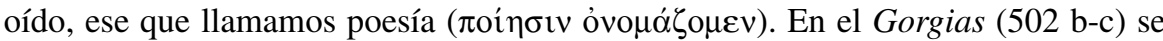
encuentra un pasaje en que se resumen estas dos perspectivas -diríamos hoy, poético-

\footnotetext{
${ }^{4}$ En Pauly, t. II., p. 106, se hace mención de la incertidumbre sobre el origen de los ditirambos, advirtiendo el carácter no griego del término y señalando la probabilidad de que el propio dios Dioniso provenga de una cultura ajena al helenismo primitivo. En la época clásica, Aristóteles (Poética 1449a) sostiene que la tragedia provendría tanto de la improvisación melódica de los ditirambos como así también los cantos

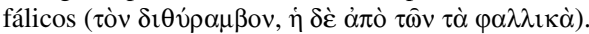

${ }^{5}$ El testimonio más tardío, pero fundamental para la tradición, proviene de la Suda bizantina, letra theta,

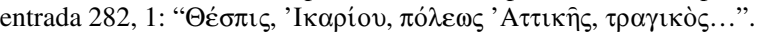


plásticas- referidas explícitamente a la poesía trágica puesta en escena. Dice allí el diálogo platónico: "la poesía trágica [...] se dirige más al placer y a dar gusto a los

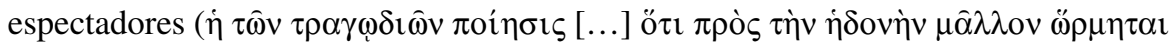

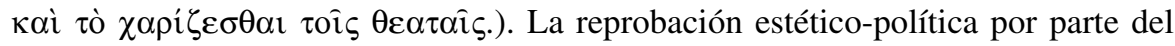
gusto aristocrático de aquello que le parece una vulgaridad inherente al teatro -compartida aquí plenamente por Platón- está presente ya en la mera noción que designa al arte teatral, pues la palabra griega $\theta \dot{\alpha} \alpha \tau \rho$ v no alude al trabajo creador relativo a la representación misma -a la puesta en escena que involucra texto, actuación y escenografía-, sino que proviene de la acción receptiva que denomina a la "masa de los espectadores" $(\theta \varepsilon \hat{\alpha} \sigma \theta \alpha \mathrm{l})$. Un cierto desprecio por el espectáculo popular se encuentra, pues, siempre presente en los diversos intentos por repudiar la festividad participativa implícita a la antigua poesía trágica y su carácter público. Sin embargo, no se trata solamente de una distancia frente al "gusto" corriente, sino que aquello que esta filosofía del período clásico parece rechazar de antemano posee también fundamentos antropológicos, en la medida en que en su desvalorización de la sensibilidad

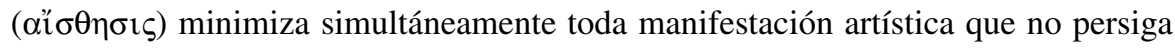

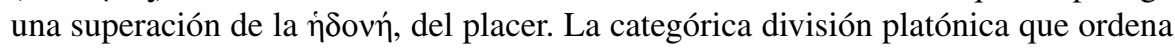

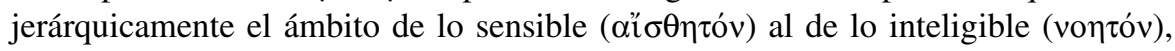
concuerda con la arcaica tesis eléatica que reduce los objetos de la sensibilidad a la

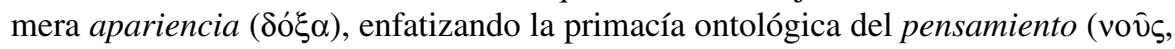

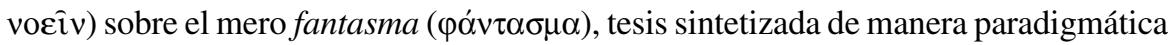

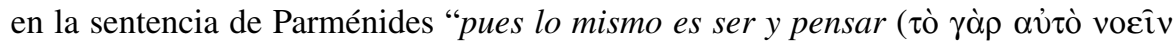

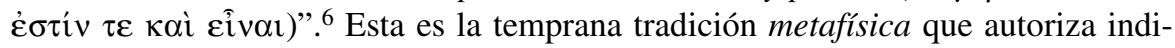
rectamente a la filosofía política platónica no sólo a instituir una ordenación social

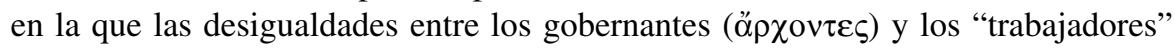
( $\delta$ нıо $\rho \gamma i$ i) se instaura a partir de la diferencia radical entre lo que actúa por causa

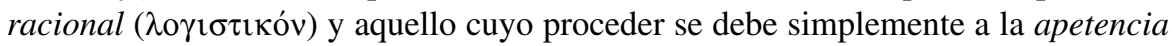

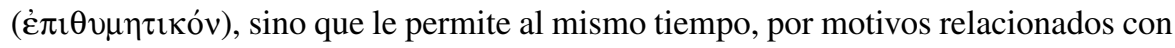
una supuesta perniciosa influencia educativa, a concluir en la conveniencia de enviar al destierro de su militarizada y opresora utópica república ( $\pi \mathrm{o} \lambda \iota \tau \varepsilon i ́ \alpha)$ a aquellos sui generis $\delta \eta \mu$ ıo

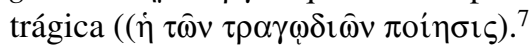

Pero el más aventajado discípulo $(\mu \alpha \theta \eta \tau \eta ́ \varsigma)$ de la Academia -según se narra en la siempre ambigua textualidad que compone ese incierto relato pseudoepigráfico que tan habitualmente se denomina historia de la filosofía- no mantuvo la necesidad de su maestro y se dispensó de la exigencia de incluir la poesía en un libro dedicado a la $\pi$ o $\lambda \iota \tau \varepsilon i \alpha$, sino que mediante una nueva taxonomía disciplinaria le confirió a la

${ }^{6}$ Cf. Die Fragmente der Vorsokratiker (fr. B 3). En su República 515 c, Platón usa la metáfora de la sombra ( $\sigma \kappa i \alpha$ ) para describir lo aparente, como cuando los prisioneros en la caverna toman por verdadero lo que no es más que las sombras de las cosas transportadas que se reflejan en el fondo de la caverna

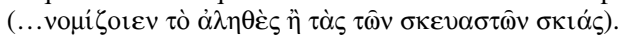

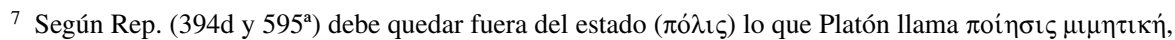
es decir, la tragedia y la comedia. Más adelante en 598 b, justifica dicha medida mediante la siguiente pregunta retórica: "Examina ahora esto: ¿qué es lo que persigue la pintura con respecto a cada objeto, imitar a lo que es tal como es o a lo que aparece tal como aparece? O sea, ¿es imitación de la realidad o

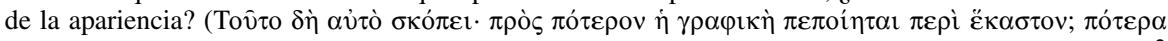

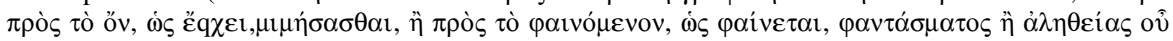
$\sigma \alpha \mu$ í $\mu \eta \imath \varsigma, ")$. 
creación trágica un acápite propio en el desarrollo de un escrito original titulado Пepi

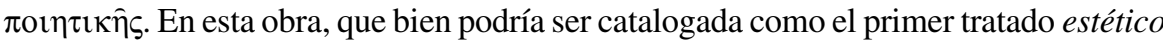
de la literatura occidental, Aristóteles formuló una definición (ópıøuós) de la poesía trágica cuyo contenido ha sido examinado de manera polémica en un lapso de tiempo que se extiende desde la Antigüedad tardía hasta la modernidad decimonónica. En la página 1449 b de la Poética se enuncia: "Es pues la tragedia imitación de una acción elevada y completa, de una determinada extensión, con un lenguaje diversamente ornado en cada parte, por medio de la acción y no de la narración, que conduce, a través de la compasión y del temor a la purificación de estas pasiones (દ̌ $\sigma \tau \imath v$ oủv

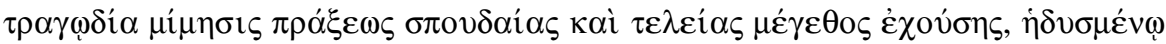

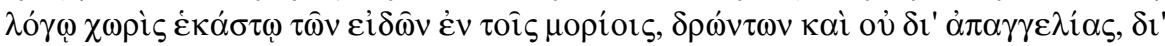

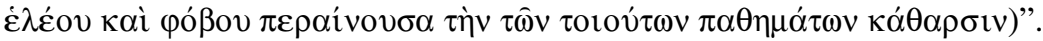

Tres aspectos contenidos en este análisis han sido decisivos para la posterior reflexión estético-literaria. En primer lugar, aquel que se refiere a la creación misma o al arte como proceso mimético; el segundo, relacionado con las consecuencias de la dramaturgia en tanto experiencia catártica, y, por último, en el caso específico de la tragedia, el efecto entre la obra de arte y el espectador queda constituido por la

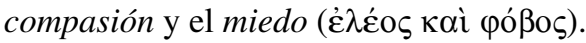

A diferencia de Platón, quien en República (594 c-d) sólo aceptaba a los poetas ditirámbicos, pues, según su tesis, éstos desarrollaban aún una narración simple

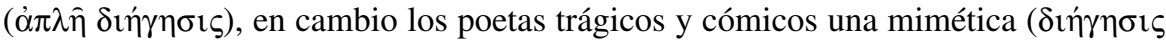

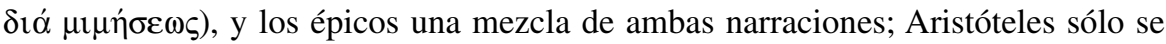
detiene en el objeto y en la forma específica de la $\mu$ í $\mu \eta \imath \iota$, buscando sus diferencias y peculiaridades, describiendo para ello el procedimiento imitativo en las diversas artes y en diferentes autores de su tiempo: "Puesto que los imitadores imitan a sujetos que actúan" -escribe al comienzo de su Poética-, "es preciso que éstos sean honestos o deshonestos (los caracteres, en efecto, casi siempre se reducen a éstos, porque todos se diferencian entre sí por su maldad o su virtud), ya sean mejores, ya peores, ya iguales a nosotros mismos. Igual cosa sucede con los pintores; Polignoto los pinta mejores, Pausón, peores; Dionisio, iguales. Es evidente que cada una de las mencionadas artes imitativas comprenderá estas diferencias y se hará diferente al imitar de tal manera diferentes objetos. También en la danza, en la flauta y en la cítara pueden hallarse dichas desemejanzas, e igualmente en los discursos y en los puros versos". 8 Ningún vestigio hay ya aquí de una posible condena al acto mimético del arte, sino sólo un énfasis especial en torno a la calidad de aquello que es imitado, lo que, a mi juicio, equivale a establecer jerarquías solamente en relación al objeto de la creación artística. En el mismo parágrafo (1448 a 16-18), Aristóteles se refiere a partir de este criterio a las artes dramáticas: "La diferencia entre la tragedia y la comedia consiste precisamente en esto: la segunda intenta representar a los hombres peores de lo que

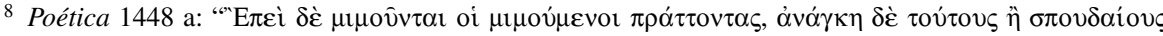

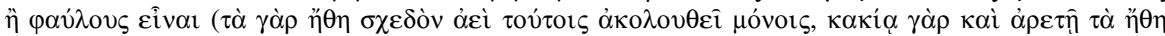

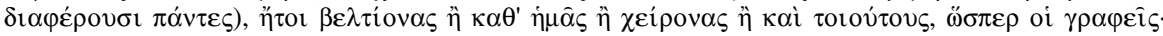

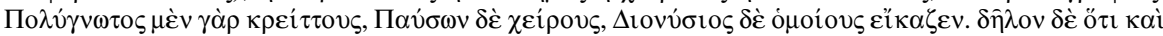

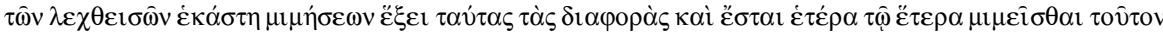

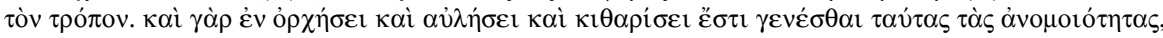

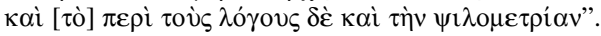




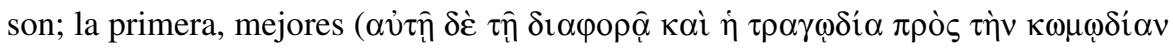

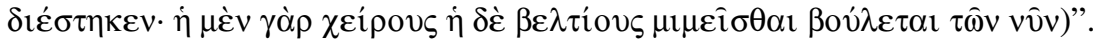

En su defensa de la mímesis, Aristóteles va incluso más allá de esta mera constatación estilística en torno a lo imitado, pues en un célebre pasaje (1451 a 36-1451 b 7) agrega que la poesía no se encuentra obligada a realizar su obra mediante una referencia a algo realmente sucedido, como se exige, por ejemplo, a la narración proveniente de la historia, sino que basta con que su objeto aluda a lo que podría suceder

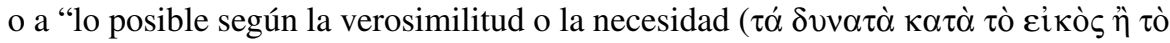

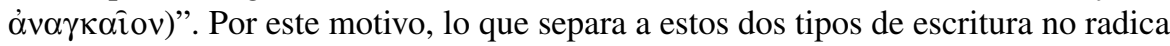
en la distinción entre relatos en verso ( diferencia se constituye en el hecho de que el historiador dice lo que ha sucedido

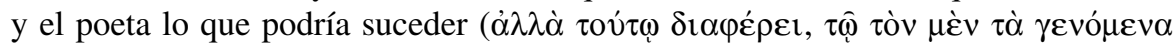

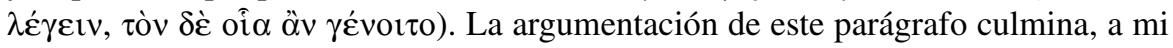
juicio, con una afirmación claramente antiplatónica, pues Aristóteles sostiene que esta diferencia es causa de que la poesía sea más filosófica y elevada que la historia ( $\delta$ iò

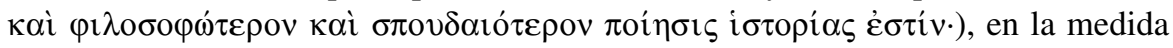

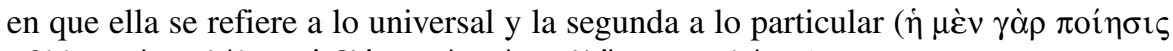

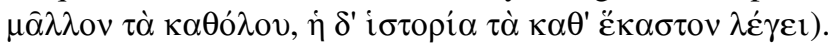

La milenaria recepción de estos textos fragmentarios de Aristóteles ha producido centenares de interpretaciones diversas de su Poética, especialmente de la definición

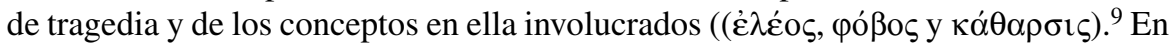
este contexto sólo quisiéramos resaltar aquí el hecho de que la recepción decimonónica enfatiza a su vez que en el corpus tragicum siempre están presentes también la ó $\mu \alpha \rho-$ $\tau i \alpha$ o error que desencadena la acción dramática caracterizada por el padecimiento o $\pi \alpha ́ \theta$ o $\varsigma$ del personaje, el que en cierto momento experimenta el reconocimiento

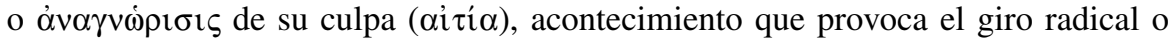
$\pi \varepsilon \rho \imath \pi \varepsilon ́ \tau \varepsilon \imath \alpha$ del relato.

Se puede afirmar con fundamentos que hasta la época de Lessing la recepción de la Poética de Aristóteles había permanecido inalterada y la concepción del arte como mímesis en ella planteada parecía haber sido compartida plenamente por pensadores, dramaturgos y artistas durante varias generaciones (cf. Petersen 2000). También se aprecia cierta homogeneidad en el modo de concebir la tragedia, aunque en el entorno ilustrado -así lo muestra la discusión epistolar sobre dramaturgia entre Lessing, Moses Mendelssohn y Friedrich Nicolai- se produce una interpretación extraña y extemporánea de la definición aristotélica, como lo evidencia la paulatina identificación de

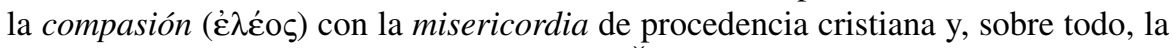
moralizante comprensión de la catarsis (cf. Žmegač $1994 / 96$ t. I/1. p. 129 y ss.). ${ }^{10}$

\footnotetext{
9 En su edición trilingüe (griego, latín, castellano) de la Poética, alude Valentín García Yebra a un compendio bibliográfico del texto elaborado en 1928 que distinguía mil doscientas sesenta y una "posiciones" distintas sobre este pasaje.

10 Cf. Brifwechsel über das Trauerspiel, especialmente la carta de F. Nicolai a Lessing del 31 de agosto de 1756 y la respuesta de éste en noviembre del mismo año (Lessing, t. 4, p. 155 y ss. y 159 y ss.). Más
} 


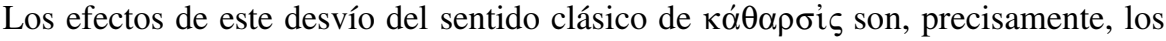
que motivan al Goethe tardío a inmiscuirse en la después de más de medio siglo aún vigente polémica mediante su breve ensayo Nachlese zu Aristoteles' "Poetik", en el que se opone a las tesis que sostienen un fin moral de la actividad artística, delegando la consecución de piedad y deber (Pietät und Plicht) a la religión y a la filosofía. Goethe vuelve a la definición aristotélica a partir de un análisis ejemplar de la catarsis del personaje de Edipo en Colono de Sófocles y propone no traducir кá $\theta \alpha \rho \sigma \iota \varsigma$ por Reinigung (purificación) sino por Ausgleichung o Versöhnung (reconciliación) de las pasiones, evitando así cualquier interpretación moral de esta determinación de la tragedia (cf. Goethe, BA t. 18, p. 121 y ss.) ${ }^{11}$.

Sin embargo, el momento decisivo de una nueva apropiación de la herencia griega en el siglo XIX estará marcado por un claro intento de comprender el presente. Así, la publicación de los estudios de Winckelmann, los viajes de Lord Byron y el explícito respaldo europeo a los griegos de la diáspora en su lucha contra la dominación del reino otomano y el consiguiente philohellenismo compartido por las casas aristocráticas de inspiración romántica, deben ser leídos, a mi juicio, como los signos de aquello que Schiller llamará más tarde Graecomanía y que la historia de la literatura (cf. Žmegač 1994/96 t. II. p. 107) ha identificado con la simultánea aparición -a mediados de la década del noventa del siglo XVIII- de su obra Über naive und sentimentalische Dichtung y del ensayo de Friedrich Schlegel Über das Studium der Griechen und Römer. Clasicismo y Romanticismo comparten, de esta manera, el inicio de una hermenéutica de las obras de la antigüedad griega que se encuentra al servicio de una interpretación de la propia modernidad literaria. El paralelismo entre tragedia clásica y drama moderno se refleja, por ejemplo, en que Schiller no vacila en subtitular su drama La Doncella de Orleans como una tragedia romántica, o que añada un prólogo-ensayo al drama Die Frau von Messina titulado Sobre el uso del coro en la tragedia. (Schiller: SW, t. 2, p. 687 y ss. y 815 y ss). Tampoco duda en denominar Sobre el arte trágico (cf. Schiller SW, t. 5, p. 372 y ss.) a un ensayo sobre los afectos cuya argumentación se fundamenta -aun cuando desarrolla una explicación de la definición aristotélica- en el empirismo, tanto sensualista como racionalista, de la para él reciente tradición anglosajona, no sólo de Hobbes, sino también de Shaftesbury y Ferguson y en la "filosofía popular alemana" (Safranski 2004, 65 y ss.) y que aspira a poder establecer -partiendo de una "fenomenología" del afecto de la compasión (Mitleid) frente al sufrimiento- las condiciones para el arte trágico ideal de la actual dramaturgia. Su modo de relacionar la experiencia artística de la Grecia clásica con la literatura moderna no se restringe solamente a este ámbito teórico, sino que se expresa asimismo en la propia creación poética, pues junto con dirigirse con nostalgia estética a los tiempos en que los dioses gobernaban "el bello universo", época en que "el velo de la poesía aún envolvía graciosamente a la verdad" y en la que no había

adelante (p. 192) describe Lessing en carta a Moses Mendelssohn del 18 de diciembre del mismo año, su modo de entender la $\dot{\alpha} \mu \alpha \rho \tau i ́ \alpha$ en el personaje trágico.

11 En su autobiografía Wahrheit und Dichtung, sostiene Goethe en relación al tratado de estética Allgemeine Theorie der Schönen Kunste de Sulzer que "una buena obra de arte puede y tendrá verdaderamente consecuencias morales; pero exigirle al artista una finalidad moral equivale a estropearle su instrumento (... ein gutes Kunstwerk kann und wird zwar moralische Folgen haben, aber moralische Zwecke vom Künstler fordern, heißt ihm sein Handwerk verderben)" Cf. Goethe: HA, X, p. 538-539. 
"nada más sagrado que lo bello" (nichts heilig als das Schöne), el célebre poema Los dioses de Grecia ${ }^{12}$ constata al mismo tiempo la pérdida irreparable de la antigua $\varphi v ́ \sigma ı \varsigma$ suplantada por la moderna "desdivinizada naturaleza" (entgötterte Natur) y concluye señalando con tono trágico "lo que ha de vivir inmortal en el canto, debe perecer en la vida". Más radical aún suenan los versos del poema Nänie, canto de duelo por la

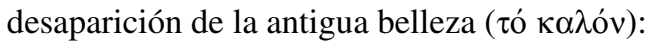

“También lo bello está destinado a morir!
(...)
¡Mira! Allí a los dioses y todas las diosas en llanto
porque lo bello pasa, porque lo perfecto muere”. ${ }^{13}$

El naciente Romanticismo de la Escuela de Jena, denominado en lengua alemana con la expresión técnica Frühromantik, también se entiende a sí mismo, y por lo tanto, a la modernidad literaria, como heredero de la poética trágica de la Grecia clásica. El joven Friedrich Schlegel dedica gran parte de sus "años preparatorios” al estudio de la poesía griega (épica, lírica, trágica), intentando una taxonomía literaria que la ordene en un contexto histórico que supere la Querrelle des Anciens et des Modernes, como lo señala la siguiente anotación en sus Fragmentos sobre literatura y poesía: "Los tres géneros poéticos dominantes: 1) tragedia para los griegos, 2) sátira para los romanos, 3) novela para los modernos" (cf. KFSA, XVI, p. 88.). En concordancia con los testimonios acerca del origen de la poesía trágica de Aristóteles y Diógenes Laercio antes mencionados ${ }^{14}$, Schlegel busca no sólo reconstruir la historia de la tragedia ática, sino que se propone además interpretarla a partir de un paradigma teleológico que involucra génesis, culminación y decadencia de este género literario de la Antigüedad. Así escribe en su obra temprana Sobre el estudio de la poesía griega: "Esquilo había inventado la tragedia con auténtica fuerza creadora (Schöpferkraft), había trazado sus contornos, determinando sus límites, su orientación y meta. Lo que bosquejó el audaz lo realizó Sófocles. Dio forma a sus invenciones, suavizó sus durezas, llenó sus huecos, consumó el arte trágico (vollendete sie tragische Kunst) y alcanzó la más alta meta de la poesía griega" (FSKA, I, p. 296). ${ }^{15}$ Tres años más tarde, un pasaje de su Diálogo sobre la poesía completaba este modelo hermenéutico o "Kanon der griechischen Tragödiendichter" (cf. Behler 1988: 20) cuya validez no sería puesta en duda durante todo el siglo XIX, siendo adoptado no sólo por Hegel y el idealismo, sino también por el joven Nietzsche. Escribe allí Schlegel: "Si Esquilo es una eterna figura originaria de la ruda grandeza y del entusiasmo no educado [esto significa, a mi juicio, que es

\footnotetext{
12 Die Götter Griechenlandes fue publicado primero el año 1788, una segunda versión apareció el año 1800. Cf. SW I, 163-168 y 169-173.

13 "Auch das Schöne muß sterben!

(...)

Siehe! Da weinen die Götter, es weinen die Göttinnen alle,

Daß das Schöne vergeht, daß das Vollkommene stirbt”.

14 Compárese la nota 3.

15 Schlegel entiende en esta misma obra la tragedia de Sófocles no sólo como el mejor exponente del género, sino además como la plenitud de la literatura griega desde sus comienzos y como una síntesis epocal: "El ritmo de Sófocles une el flujo poderoso, la concentrada fuerza y la dignidad viril del estilo dórico con la rica plenitud, la pronta elisticidad y la tierna ligereza de los ritmos jónicos o eólicos” (KFSA II, p. 300).
} 


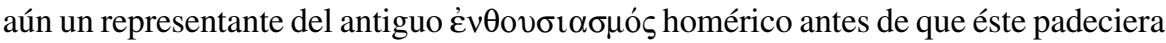
la intervención "político-civilizatoria" de la $\pi \alpha \_\delta \varepsilon i ́ \alpha$ clásica] ${ }^{16}$ y Sófocles lo es, en cambio, de la plenitud armoniosa (harmonischen Vollendung), Eurípides muestra ya aquel insondable agotamiento que sólo es posible en un artista decadente y su poesía es a menudo tan sólo la más ingeniosa declamación” (KFSA, II, p. 293). ${ }^{17}$ Es sorprendente, asimismo, poder corroborar en relación a esta última cuestión la plena coincidencia que se produce entre la teoría de la tragedia de los hermanos Schlegel y el análisis posterior de Nietzsche, ${ }^{18}$ pues en ambas interpretaciones se entiende que el ocaso de la poesía trágica expresado en la obra de Eurípides habría sido causado por una excesiva injerencia de la filosofía, transformando el lenguaje dramático de los personajes trágicos en reflexiones lógicas que ya no permitían experimentar la tensión conmovedora provocada por el inevitable cumplimiento del destino ni tampoco padecer los efectos de aquella acción movida por cierta ineludible fatalidad. La diferencia de estas propuestas hermenéuticas de lo trágico radica solamente en el hecho de que mientras los hermanos Schlegel identifican tal intromisión con la filosofía de Anaxágoras, Nietzsche, como se sabe, la vincula con el discurso lógico-mayéutico de Sócrates. La coincidencia vuelve a producirse, no obstante, cuando se trata de caracterizar la tragedia moderna, pues tanto Friedrich Schlegel como Nietzsche ven dicha realización en el Hamlet de Shakespeare (cf. Behler 1998: 200)

Aun cuando se puede adherir sin mayores resistencias al significado primordial de esta exégesis y aceptar parcialmente la tesis de la "muerte de la poética griega en manos de la filosofía con la complicidad de Eurípides", ${ }^{19}$ no deja de llamar la atención, sin embargo, que en el mismo siglo XIX se haya producido una de las más fructíferas recepciones del sentido de lo trágico por parte de la filosofía. Me refiero al modo en que la literatura trágica es integrada a la exposición "científica" en la filosofía del espíritu de Hegel. Si bien es cierto que en el siglo XX, especialmente en la tradición anglosajona y en los historiadores de la literatura griega se ha tendido a criticar como falsa lo que se ha denominado la teoría hegeliana de la tragedia (cf. Lesky 1989, p. 307), parece oportuno insistir aquí, por otra parte, en el hecho de que su aproximación al sentido de ese arte literario de la antigüedad, tuvo una gran influencia en todas las corrientes filológico-filosóficas de la segunda mitad del

\footnotetext{
16 Schlegel no usa el vocablo alemán Begeisterung sino que transcribe sencillamente el término griego

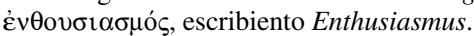

17 En sus Lecciones sobre la filosofía de la historia universal señala Hegel, luego de describir el ambiente igualitario y libre de la Atenas de Pericles: "Ante este pueblo fueron representados los dramas de Esquilo y Sófocles, y más tarde los de Eurípides, que ya no tienen, sin embargo, el mismo carácter plástico y en los cuales se reconoce ya el principio de la decadencia (Prinzip des Verderbens)”'(W, XII, p. 317). Más drástico aún es el juicio de Nietzsche. Entre los múltiples pasajes referidos a esta cuestión, destaca el siguiente, tomado de su obra juvenil El nacimiento de la tragedia: "Dioniso había sido ahuyentado ya de la escena trágica, y lo había sido por un poder demónico que hablaba por boca de Eurípides. También Eurípides era, en cierto sentido, solamente una máscara: la divinidad que hablaba por su boca no era Dioniso, ni tampoco Apolo, sino un demón que acababa de nacer, llamado Sócrates. Esta es la nueva antítesis: lo dionisíaco y lo socrático, y la obra de arte de la tragedia pereció por causa de ella (das Kunstwerk der griechischen Tragödie ging an ihm zu Grunde) (KSA I, p. 81).

18 Digo "coincidencia" porque es imposible afirmar que Nietzsche haya conocido los escritos de los hermanos Schlegel en los que se desarrolla dicha teoría.

19 Tesis repudiada, por cierto, por la filología clásica de la época, especialmente por Ulrich von WillamowitzMöllendorf en su crítica titulada Zukunftphilologie! de 1872, en la cual acusa a Nietzsche de ignorancia (Unwwissenheit) y de falta de amor a la verdad (Mangel an Wahrheitsliebe).
} 
siglo XIX. (cf. Bremer 1986). Pero más importante que este efecto, que bien podría denominarse externo, me parece este otro de carácter intrínseco al pensamiento de Hegel: me refiero al modo en que la tragedia opera en la filosofía del espíritu como parte de la constitución sistémica de la ciencia o Wissenschaft. En este sentido, no debe dejar de sorprender, en primer lugar, el hecho de que cuando la contribución del antiguo sentimiento trágico en su sentido radical - señalo con ello el valor de una experiencia vital del destino ( $\dot{i} \mu \alpha \rho \mu \varepsilon ́ v \eta)$ en el contexto forzosamente pretérito de un cosmos polidivino- parecía ya totalmente superado por la teología redentora del dios único, la filosofía del occidente decimonónico haya tenido una inesperada necesidad por volver a "tomar en serio" el significado de dicha tradición y la haya podido integrar a las cuestiones propias que su época experimentaba como apremiantes. $\mathrm{Si}$ hubiese que señalar un rasgo distintivo de la manera en que se distingue la obra de Hegel en la historia de la filosofía de la modernidad hasta nuestros días, creo que se podría indicar, sin vacilación, su enorme capacidad de retribuir significado al pasado histórico en sus diversas expresiones, sin que ello le impida proyectar con resolución un futuro incierto y a vivir, además, en mesurada plenitud su propio presente. Por otra parte, es característico de la filosofía del espíritu otorgar el mismo rango ontológico a diversas expresiones que componen el contenido (Inhalt) concreto de la realización del espíritu. Así, Hegel puede ejemplificar los diversos momentos constitutivos del despliegue espiritual recurriendo al significado paradigmático de un hecho histórico -como la Revolución Francesa y la Reforma Protestante- o a una personalidad de la historia política o del pensamiento, pero también se refiere a la institucionalidad del Estado o a una obra de arte plástico o literario. ${ }^{20}$

En relación a la tragedia ática y sus potencialidades ejemplares para la historia del espíritu, el pensamiento decimonónico advierte la necesidad de romper con un largamente consagrado prejuicio hermenéutico en el que el sentido del destino (Schicksal,

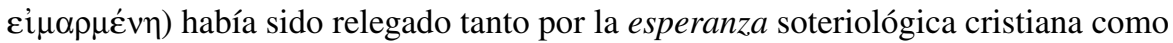
por la racionalidad ilustrada a la mera fatalidad, privándolo de manera infundada de una fuerza de significado que pudiese ser conveniente a la descripción de la experiencia existencial y su praxis. "El fatum" -replica Hegel en sus Lecciones sobre la Filosofía de la Religión (W. 17, p. 131) "es lo falto de concepto (Begrifflose), en el que justicia e injusticia desaparecen en la abstracción; en la tragedia, en cambio, el destino (Schicksal) se produce dentro de un círculo de justicia ética (eines Kreises sittlicher Gerechtigkeit). Esto lo encontramos de la manera más elevada en las tragedias de Sófocles. Lo mismo se dice del destino y la necesidad; el destino de un individuo es expuesto como algo inconcebible, pero la necesidad no es ciega, sino que ella es reconocida como la justicia verdadera. Por eso las tragedias son inmortales obras espirituales de la comprensión y la concepción ética (des sittlichen Verstehens), el eterno ejemplo del concepto ético (die ewigen Muster des sittlichen Begriffs.)".

Junto con recuperar el contenido del destino para el concepto, es decir, para el pensamiento especulativo o ciencia filosófica, este breve párrafo señala además la

${ }^{20}$ La parte del sistema correspondiente a la filosofía del espíritu toma su contenido de la historia universal, la historia de la filosofía, el pensamiento jurídico, la religión y el arte. Cada uno de estos ámbitos fue desarrollado por Hegel bajo la forma de lecciones universitarias que se conservan como manuscritos (Vorlesungsmanuskripten), sólo las Lecciones sobre la Filosofía del Derecho se transformaron en una publicación bajo la forma de libro. 
circunstancia en la que debe situarse el rendimiento paradigmático de la tragedia en la composición de la historia del espíritu. Distanciándose de la filosofía de Kant y de sus epígonos, el sistema de Hegel no reconoce a la eticidad o Sittlichkeit como una región autónoma del saber que pudiese reclamar para sí un tratado específico, al modo de una crítica de la razón práctica, sino que ella se manifiesta como el momento dialéctico constitutivo del espíritu inmediato (unmittelbare Geist), y en calidad de tal es integrada la Sittlichkeit a la filosofía de Hegel, ya sea en la exposición temprana de la Fenomenología del espíritu de 1807 o en las diversas versiones de la Enciclopedia. ${ }^{21}$

Un énfasis sutilmente distinto sobre esta misma cuestión se percibe en el siguiente pasaje de las lecciones sobre Estética o Filosofía del arte: "En general podemos [...] decir que el tema propio de la tragedia originaria (der ursprünglichen Tragödie) es lo divino; pero no lo divino tal como esto constituye el contenido de la consciencia religiosa como tal, sino tal como interviene en el mundo, en la acción individual, no obstante sin merma de esta realidad efectiva de su carácter sustancial y sin verse transformado en lo contrario a sí. En esta forma la sustancia espiritual del querer y del consumar es lo ético (das Sittliche). Pues lo ético, si lo concebimos en su solidez inmediata y no sólo desde la perspectiva de la reflexión subjetiva como lo formalmente moral (als das formell Moralische), es lo divino en su realidad mundana (in seiner weltlichen Realität), lo sustancial cuyos aspectos tanto particulares como esenciales ofrecen el contenido motor de la acción verdaderamente humana y explicitan y hacen efectivamente real en la acción misma esta su esencia" (W. 15, p. 521).

Muchas y diversas son las posibilidades de exponer la relación "apropiante" entre la filosofía hegeliana y la literatura trágica griega. Se puede, por cierto, retroceder hasta sus fragmentarios escritos juveniles y buscar indicios que vinculen la fructífera dedicación a la lectura e interpretación del drama antiguo con una empresa realizada en comunidad con la incipiente poética de Hölderlin (cf. Pöggeler 1973; Portales, 1994), o detenerse principalmente en la dicotomía que expresa el fin de la polis dentro de los marcos de la obra redactada en el período de Jena (cf. Hyppolite 1974), como así también concentrar la atención en las lecciones berlinesas sobre Estética y analizar la tragedia como aquella forma de la obra de arte que expresaría la superación (Aufhebung) de lo natural mediante el concepto de belleza (Szondi 1994). Cada uno de estos intentos tiene su fundamento y legitimidad, pero quisiera, no obstante, finalizar esta reflexión recorriendo un camino distinto al de la opción del criterio cronológico supeditado al ritmo de la construcción del sistema y ensayar una interpretación que permita una comprensión más general de la dialéctica hegeliana de lo trágico basada, sin embargo, en una singularidad ejemplar. Para ello me propongo restringir la cuestión al modo específico en que Hegel obtiene un rendimiento filosófico propio a partir de la tragedia Antígona de Sófocles mediante lo que podríamos llamar una fenomenología de la Sittlichkeit o eticidad.

\footnotetext{
${ }^{21}$ He optado por mantener la ya habitual traducción del vocablo alemán Sittlichkeit por el término castellano eticidad y del adjetivo sichttlich por ético, aun cuando tal proceder no está exento de dificultades, pues aunque ambos términos reflejan el sentido del antiguo ethos, su significado puede ser traicionado por el uso abusivo del concepto de ética en la actualidad. Sittlichkeit contiene en su campo semántico una clara intención de referencia a la praxis humana, al carácter específico de la acción al interior de la comunidad y la familia y apunta también al resguardo de una tradición consuetudinaria.
} 
Aludiendo directamente a esta obra trágica y, tal vez, también a la enigmática sentencia $\hat{\eta} \theta$ o $\varsigma \dot{\alpha} v \theta \rho \omega \dot{\pi} \omega \mathrm{l} \delta \alpha \dot{\mu} \mu \omega \mathrm{v}$, conservada por la tradición doxográfica como uno de los fragmentos de Heráclito y que traducimos "para el hombre el ethos es un Daimon", Hegel sostiene en diversos pasajes que lo propio de aquello que llamamos "leyes éticas" es que simplemente son, y agrega que "por eso ellas valen para la Antígona de Sófocles como el derecho no escrito e infalible de los dioses" y cita los versos 456-457:

"No de hoy ni de ayer, sino de siempre

Este derecho vive, y nadie sabe cuando ha aparecido"

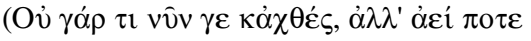

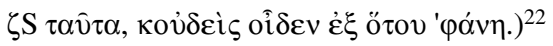

Una primera aproximación interpretativa a este párrafo del acápite que en la estructura de la Fenomenología señala el paso desde la razón legislativa al espíritu verdadero permite inferir que Hegel, en concordancia con los antiguos, entiende el ethos como un constitutivo ontológico del hombre (Mensch, öv $\theta \rho \omega \pi \mathrm{s}$ ) cuyo sentido y origen, como en el caso del hombre mismo, no pueden ser objeto de una pregunta por su causalidad. Casi se podría decir, en tono trágico, que el ethos es el destino propio del anthropos. La consecuencia más inmediata de esta afirmación es que no se puede ni se debe buscar un fundamento (Grund) de los contenidos específicos del ethos más allá de la praxis humana supeditada a los dioses. En las lecciones berlinesas sobre Filosofía de la historia, sin embargo, esta misma alusión posee un suplemento que busca, a mi juicio, eliminar una posible ambigüedad. Repite allí Hegel, en el contexto de la exposición sobre la relación entre individuo y estado, los versos recién citados: "Antígona dice en la obra de Sófocles: los mandatos divinos no son de ayer ni de hoy, no; viven sin término y nadie sabría decir de cuándo son". Y agrega a continuación: "Las leyes de la eticidad no son casuales, sino lo racional mismo (Die Gesetze der Sittlichkeit sind nicht zufällig, sondern das Vernünftige selbst)". (W. 12, p. 55). No es evidente, pues, el modo en que se deba interpretar esta relación de lo ético por un lado con lo que los antiguos denominaron púoıৎ y a la vez con lo racional o Vernünftige.

Las Lecciones sobre Estética vuelven sobre este asunto subrayando que cuando de lo que se trata es del sentir y actuar humanos (das menschliche Empfinden uns Handeln), esta doble dirección queda sintetizada en la figura -divina para los griegos- de la justicia ( $\Delta \mathbf{i} \kappa \eta)$. Escribe allí Hegel en un renombrado pasaje (W. 14, 59) que ha provocado insospechadas y fructíferas lecturas en la discusión contemporánea (cf. Lucas 1998): “Todo en esta tragedia [Antígona] es consecuente: la ley pública del estado está en abierto conflicto con el íntimo amor familiar y el deber para con el hermano; la mujer, Antígona, tiene como pathos el interés familiar; Creonte, el varón, el bienestar de la comunidad. Combatiendo contra la propia ciudad natal, Polínice había caído ante las puertas de Tebas, y Creonte, el soberano, amenaza con la muerte, mediante una ley públicamente difundida, a quien dé el honor de la sepultura a aquel enemigo de la ciudad. Pero Antígona no puede aceptar esta orden, que sólo afecta al bien público del estado, y cumple como hermana con el sagrado deber de sepultura

22 Se trata de un célebre pasaje de la Fenomenología del espíritu (cf. W. 3, 21). 
por la piedad del amor hacia su hermano. Invoca entonces la ley de los dioses; pero los dioses que ella venera son los dioses inferiores del Hades (Sófocles, Antígona, v. 451,

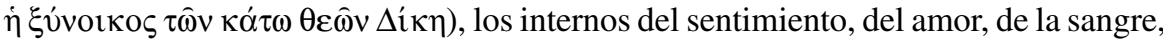
no los dioses de la luz de la vida libre y autoconsciente del pueblo y del estado."

La contradicción entre estado y familia, varón y mujer, público y privado, ejemplificada en el Cosmos antiguo como la oposición entre Zeus y Dike constituye pues al ámbito de apertura en que se realiza la acción ética, la cual expresa para Hegel un tipo de escisión que bien puede ser reconocida en la obra de arte trágica, en donde el acto humano conduce al sufrimiento y no por eso su motivación deja de tener un fundamento que la justifica. En la Fenomenología (W. 3, 347) ya se había

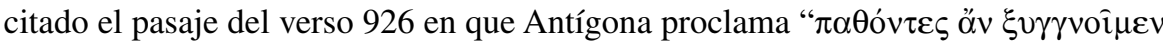
$\dot{\eta} \mu \alpha \rho \tau \eta \kappa o ́ \tau \varepsilon \varsigma$ (porque sufrimos, reconocemos que hemos cometido falta)". ${ }^{23}$ La relación entre literatura trágica y filosofía del espíritu parece señalar que la obra de arte no sólo debe ser comprendida como un objeto propio del pensamiento estético, sino que ella puede ser también una ejemplaridad sobresaliente del acto espiritual proveniente del ethos. Tal vez sería conveniente retomar la reflexión en el sentido aquí señalado, sobre todo en una época como la actual, en la que la sobreproducción textual y simbólica en torno a la "ética" ha hecho casi desaparecer la aporía trágica presente en sus orígenes. Situación expresada paradigmáticamente en el Coro de Antígona:

v. 334 "Muchas cosas asombrosas existen, y con todo, nada más asombroso que

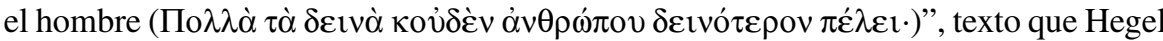
junta en la Enciclopedia (cf. W. 9, 12) ${ }^{24}$ con el verso 360: "Nada de lo porvenir le

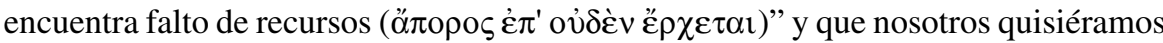
vincular también con los versos 364-365 del mismo coro: "Poseyendo una habilidad superior a lo que se puede uno imaginar, la destreza para ingeniar recursos, la encamina

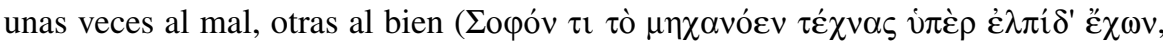

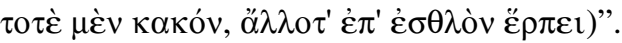

\section{OBRAS CITADAS}

Behler, Ernst. 1988. Studien zur Romantik und zur idealistischen Philosophie. Paderborn: Schöning.

Bremer, Dieter. 1986. Hegel und Aischylos. Hegel-Sudien, Beiheft 27, p. 225- 244.

Lessing, Gotthold Ephraim. 1970. Werke. Ed. de Herbert G. Göpfert et al. 8 volúmenes. München: Hanser.

\footnotetext{
23 En este lacónico verso se encuentran presentes aquellos conceptos, antes mencionados, que Aristóteles describe como componentes del arte trágico: $\pi \dot{\alpha} \theta 0 \varsigma$-sufrimiento- y $\alpha \mu \alpha \rho \tau i ́ \alpha$-error. Otra versión de esta cita se encuentra en las Lecciones de Historia de la Filosofía (cf. W. 18, 508) a propósito del destino de

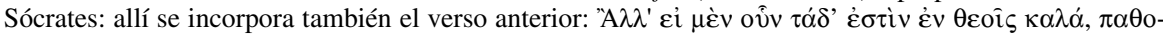

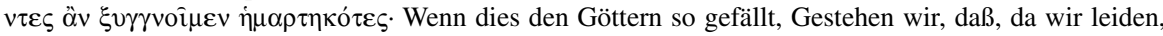
wir gefehlt.

24 Aunque la traducción castellana de $\tau \grave{\alpha} \delta \varepsilon \iota v \grave{\alpha}$ por "cosas asombrosas" y del comparativo $\delta \varepsilon ı v o ́ \tau \varepsilon \rho o \zeta$ como "más asombroso que" es correcta, habría sin embargo que señalar que el adjetivo $\delta \varepsilon ı$ có significa también "temible" y "espantoso". Hegel prefiere, por tanto, la traducción "Ungeheuer", que parece adecuarse mejor al así llamado "pesimismo antropológico" de Sófocles y que subraya la apertura de posibilidades inherente a los efectos de la praxis proveniente del ethos.
} 
Lucas, Hans Christian. 1988. Zwischen Antigone und Christiane. Die Rolle der Schwester in Hegels Biographie und Philosophie und in Derridas "Glas". Hegel-Jahrbuch 1984/85, p. 409-442.

Goethe, Johann Wolfgang. 1960 y ss. BA (Berliner Ausgabe). Ed. de Siegfried Seidel, 22 volúmenes. Berlin: Aufbau.

Hegel, G.W.F. 1970. Werke in 20 Bänden (= W). Frankfurt am Main: Suhrkamp.

Hyppolite, Jean. 1974. Génesis y estructura de la "Fenomenología del Espíritu” de Hegel. Barcelona: Península.

Pöggeler, Otto. 1973. Hegels Idee einer Phänomenologie des Geistes. Freiburg/München: Karl Alber.

Portales, Gonzalo. 1994. Hegels frühe Idee der Philosophie. Stuttgart-Bad Cannstatt: FrommannHolzboog.

Schiller, Friedrich. 1962. SW (Sämtliche Werke). Ed. de Gerhard Fricke y Herbert G. Göpfert, 5 volúmenes. München: Hanser.

Steiner, Georges. 1996. Antígonas. Una poética y una filosofía de la lectura. Barcelona: Gedisa.

Szondi, Meter. 1974. Poetik und Geschichtsphilosophie I. Frankfurt am Main: Suhrkamp.

Žmegač, Viktor (ed.). 1994/96. Geschichte der deutschen Literatur vom 18. Jahrhundert bis zur Gegenwart. Tres volúmenes. Beltz Athenäum: Verlag. 